\title{
Relationship between Vitamin D Deficiency and Insulin Resistance in Obese Children
}

\author{
Aidah Juliaty ${ }^{1}$, Putri Lestari Gabrilasari ${ }^{1}$, Dasril Daud $^{1} \&$ Johan Setyawan Lisal $^{1}$ \\ ${ }^{1}$ Department of Pediatrics, Hasanuddin University's Faculty of Medicine, Indonesia \\ Correspondence: Aidah Juliaty, Department of Pediatrics, Hasanuddin University's Faculty of Medicine, Jl. \\ Perintis Kemerdekaan km. 10, Tamalanrea, Makassar, Indonesia.
}

Received: October 15, 2020 Accepted: November 27, 2020 Online Published: December 8, 2020

doi:10.5539/gjhs.v13n1p82 URL: https://doi.org/10.5539/gjhs.v13n1p82

\begin{abstract}
Introduction: Obesity represents the major risk factor for development of insulin resistance during childhood and adolescents. In obesity, adipose tissue release free fatty acids, various hormones, and cytokines, resulting in insulin resistance. This study aimed to establish the correlation between vitamin D deficiency and the incidence of insulin resistance in obese children.

Design and Method: This analytical cross-sectional study was arranged from December 2019 - February 2020 included 96 students aged 11-17 years old from junior and senior high school who met the criteria for obesity in Makassar. The study subjects were parted into two groups, obese children with vitamin D deficiency (levels of 25-hydroxyvitamin D $\leq 20 \mathrm{ng} / \mathrm{ml}$ ) and obese children without vitamin D deficiency group (levels of 25-hydroxyvitamin $\mathrm{D}>20 \mathrm{ng} / \mathrm{ml}$ ). Data were analyzed using univariate and bivariate analysis.

Results: The frequency of insulin resistance in obese children with vitamin D deficiency was 28 (54.9\%), while obese children without vitamin D deficiency was 10 (22.2\%). Based on statistical analysis, the frequency of the occurrence of insulin resistance in vitamin D deficiency obese children was higher than in obese children without vitamin D deficiency with $\mathrm{OR}=4.261(95 \%$ CI $1.744-10.411), \mathrm{p}=0.001$.
\end{abstract}

Conclusion: The risk of insulin resistance in obese children with vitamin D deficiency is 4.261 times higher than obese children without vitamin D deficiency.

Keywords: vitamin D deficiency, insulin resistance, obese children

\section{Introduction}

Deficiency of vitamin D is an important issue in the world that involves all ages including children, and it is associated with levels of adiposity (Peterson, 2015). A previous study reported that $50 \%$ of obese adolescents in Poland have vitamin D deficiency (Garanty-Bogacka et al., 2011). A study of 125 obese children in Germany, found that $75 \%$ of subjects have vitamin D deficiency $(<20 \mathrm{ng} / \mathrm{ml}$ ) (Roth et al., 2011).

Vitamin D deficiency in obesity resulting from increased inflammation in muscle cells and increased infiltration of immune cells and pro-inflammatory activation of perimuscular and intramyocellular adipose tissue. With the secretion of pro-inflammatory molecules, immune cells induce inflammation of myocytes and developing insulin resistance through the paracrine effect (Wu \& Ballantyne, 2017).

The link between vitamin D with obesity is not only a condition of vitamin D accumulation in adipose tissue but also higher leptin levels. Leptin through Fibroblast Growth Factor-23 (FGF-23), a phosphaturic factor that importance in the metabolism of vitamin D in the kidneys, suppresses the synthesis of 1,25-hydroxyvitamin D, which is the active form of vitamin D in the kidneys. Besides, leptin directly suppress circulating 25-hydroxyvitamin D binding with 1-hydroxylase (CYP27B1) and 1,25-hydroxyvitamin D 24-hydroxylase (CYP24) in kidney and adipose tissue. There is also a theory which states that with an increase in adipose tissue, fat-soluble vitamin D will be stored in adipose tissue, causing vitamin D deficiency (Peterson, 2015).

A study showed that deficiency of vitamin $\mathrm{D}$ has an important role as well as a risk factor for insulin resistance (Sung et al., 2012). The 1.25-dihydroxy vitamin D signal in Vitamin D Receptors (VDRs) induces insulin to uptake glucose in the liver, adipose tissue, and skeletal muscle. 1.25-dihydroxy vitamin D directly activates transcription and expression of insulin receptor genes and protein. It also increases the expression of GLUT-4 in muscle cells 
and induces translocation in adiposity. In obese patients, vitamin D lowers the release of cytokines and chemokines by adipocytes and chemotaxis by monocytes, as well as its effect on systemic and tissue-specific inflammation involving a variety of factors including suppression of the NF- $\kappa \beta$ pathway, inhibits the expression of toll-like receptor 4 (TLR-4), and decrease dendritic cell differentiation (Greco et al., 2019).

In obesity, there is an increase in FFA (Free Fatty Acid), various hormones, and also cytokines released by adipose tissue which results in insulin resistance. Besides, obesity causes vitamin D deficiency which also causes insulin resistance. Therefore, it is necessary to investigate the relationship between vitamin D deficiency and insulin resistance in obese children.

Insulin resistance is the basic pathophysiology of metabolic syndrome, which long-term complications are such as type 2 Diabetes Mellitus, stroke, and cardiovascular disease (Pulungan et al., 2013). Management of insulin resistance should be started at initial stage, when comorbidities such as obesity are still reversible so that the morbidity and mortality associated with metabolic syndrome decreases (Govers, 2015).

A previous study showed that $47 \%$ of insulin resistance cases could be explained by the interaction between a high BMI (Body Mass Index) and low levels of 25-hydroxy vitamin D (Kabadi et al., 2012). This statistical evidence supports the idea that the burden of insulin resistance in obese individuals could be reduced by increasing serum 25-hydroxy vitamin D levels. Considering the difficulty of managing obesity in certain individuals, recommendations to increase body vitamin D levels may be a cheaper and more practical way to reduce the burden of insulin resistance.

Vitamin D is essential in glucose homeostasis. Most studies show that vitamin D deficiency paly a role in disrupting glucose homeostasis in obese adults, however, this hypothesis is still controversial in children (Torun et al., 2013). This study was conducted to know the relationship between vitamin D deficiency and insulin resistance in obese children, because the data regarding deficiency of vitamin D in obesity and its relationship with insulin resistance are still debatable, with a lack of study in children. To the best of the writer's knowledge, this study has never been conducted in Indonesia.

Based on the explanation above, this study aimed to establish the relationship between vitamin D deficiency and the incidence of insulin resistance in obese children.

\section{Design and Method}

This analytical cross-sectional study was arranged from December 2019 - February 2020 in 96 students aged 11 17 years who met the criteria for obesity. This study has been approved by the Ethics committee of biomedical research on Human of Hasanuddin university and written informed consent has been obtained from the parents of all children.

Inclusion criteria are Junior High or Senior High school students aged 11-17 years with obesity. Children with a history of liver or kidney dysfunction, children with endocrinological disease, children in corticosteroid, antiepileptics, or anti tuberculin medication, and children who were not fasting before the blood sample was drawn were excluded. Data of age, sex, and anthropometric examination results to determine nutritional status, and laboratory examination results were recorded. Laboratory tests include: 25 -hydroxy vitamin D levels, fasting blood sugar levels, and fasting insulin levels. Blood sample examinations were conducted at the Hasanuddin University Medical Research Center (HUMRC) Laboratory in the city of Makassar. The study subjects were parted into two groups, obese children with vitamin D deficiency ((levels of 25-hydroxyvitamin D $\leq 20 \mathrm{ng} / \mathrm{ml}$ ) and obese children without vitamin D deficiency group ((levels of 25-hydroxyvitamin D $>20 \mathrm{ng} / \mathrm{ml}$ ).

Vitamin D was measured using the 25-hydroxyvitamin D enzyme-linked immunosorbent assay (ELISA) kit, colorimetric method. Fasting blood glucose was measured using blood analyzer Cobas Integra 400 Plus with Chemiluminescence method.

\subsection{Data Analysis}

Data were analyzed using univariate and bivariate analysis. Univariate analysis was used to describe the frequency, mean, standard deviation, range, and median value. Bivariate analysis including the Mann-Whitney test and Chi-Square test was used to compare the variables to determine the significance between vitamin D and the incidence of insulin resistance. Odds ratio (OR) analysis with $95 \%$ confidence interval (CI) was used to establish the risk of insulin resistance. The $\mathrm{p} \leq 0.05$ indicates statical significance.

\section{Results}

During the study period, there were 51 (53,1\%) obese children with vitamin D deficiency and 45 (46.9\%) obese children with normal vitamin D status. 
In the groups of vitamin D deficiency, the number of boys was $32(62.7 \%)$ and girls were $19(37.3 \%)$. In the groups without vitamin D deficiency, the number of boys was $25(55.6 \%)$ and girls were $20(44.4 \%)$. Statistical analysis based on the chi-square test showed that there was no significant difference in gender distribution between the groups of vitamin D deficiency and without vitamin D deficiency in obese children, with a value of $p=0.474$ ( $p>$ 0.05) (Table 1).

Table 1. Analysis of Gender Distribution in group of Vitamin D Deficiency and group without Vitamin D Deficiency in Obese Children

\begin{tabular}{lllll}
\hline \multirow{2}{*}{ Gender } & \multicolumn{2}{c}{ Vitamin D } & Total & $p$-Value \\
\cline { 2 - 3 } & Deficiency & Without Deficiency & $57(59.4 \%)$ & \\
\hline Boys & $32(62.7 \%)$ & $25(55.6 \%)$ & $39(40.6 \%)$ & $0.474 *$ \\
Girls & $19(37.3 \%)$ & $20(44.4 \%)$ & $96(100 \%)$ & \\
Total & $51(100.0 \%)$ & $45(100.0 \%)$ & & 9 \\
\hline
\end{tabular}

* Chi-square test.

The average age in the groups of vitamin D deficiency was 13.82 years old, the median value was 14.00 years old with a minimum-a maximum value of 12.08-17.08 years old. Whereas in the groups without deficient vitamin D deficiency, the mean age was 14.34 years old, the median value was 13.75 years old with a minimum-maximum value of 11.83-17.92 years old. The Mann-Whitney test showed that there was no significant difference in the mean age values between the groups of vitamin D deficiency and without vitamin D deficiency in obese children with a value of $\mathrm{p}=0.579(\mathrm{p}>0.05)$ (Table 2$)$.

Table 2. Average Age Value in group of Vitamin D Deficiency and group without Vitamin D Deficiency in Obese Children

\begin{tabular}{llll}
\hline \multirow{2}{*}{ Age (years old) } & \multicolumn{2}{c}{ Vitamin D } & $p$-Value \\
\cline { 2 - 3 } & Deficiency $(\mathrm{n}=51)$ & Without Deficiency $(\mathrm{n}=45)$ & \\
\hline Mean & 13.82 & 14.34 & $0.579 * *$ \\
Median & 14.00 & 13.75 & \\
Standard Deviation & 1.16 & 1.75 & $11.83-17.92$ \\
Minimum-Maximum & $12.08-17.08$ & & \\
\hline
\end{tabular}

** Mann-Whitney test.

The incidence of insulin resistance in obese boys was 25 (43.9\%), while in the obese girls was $13(34.2 \%)$. Statistical analysis based on the chi-square test showed that there was no significant difference in the frequency of insulin resistance based on gender in obese children, with a value of $p=0.300(p>0.05)$ (Table 3).

Table 3. Analysis of Frequency of Incidence of Insulin Resistance by Gender in Obese Children

\begin{tabular}{|c|c|c|c|c|}
\hline \multirow{2}{*}{ Gender } & \multicolumn{2}{|c|}{ Insulin Resistance } & \multirow{2}{*}{ Total } & \multirow{2}{*}{$p$-Value } \\
\hline & Yes & No & & \\
\hline Boys & $25(43.9 \%)$ & $32(56.1 \%)$ & $57(100 \%)$ & \\
\hline Girls & $13(33.3 \%)$ & $26(66.7 \%)$ & $39(100 \%)$ & $0.300 *$ \\
\hline Total & $38(39.6 \%)$ & $58(60.4 \%)$ & $96(100 \%)$ & \\
\hline
\end{tabular}

* Chi-square test.

The mean age in the groups of insulin resistance was 13.91 years old, the median value was 14.00 years old with a 
minimum-maximum value of 12.08-17.25 years old. Meanwhile, in the groups of non-insulin resistance, the mean age value was 14.16 years old, the median value was 13.79 years old with a minimum-maximum value of 11.83 17.92 years old. The Mann-Whitney test showed that there was no significant difference in the mean age values in the groups of insulin resistance and non-insulin resistance in obese children, with a value of $p=0.783(p>0.05)$ (Table 4).

Table 4. Mean Age Value in group of Insulin Resistance and group without Insulin Resistance in Obese Children in Obese Children

\begin{tabular}{llll}
\hline Age $($ years old $)$ & Insulin Resistance $(\mathrm{n}=58)$ & Without Insulin Resistance $(\mathrm{n}=38)$ & $p$-Value \\
\hline Mean & 13.91 & 14.16 & $0.733^{* *}$ \\
Median & 14.00 & 13.79 & 1.55 \\
Standard Deviation & 1.37 & $11.83-17.92$ & \\
Minimum-Maximum & $12.08-17.25$ & & \\
\hline
\end{tabular}

** Mann-Whitney test.

The incidence of insulin resistance in vitamin D deficiency obese children was 28 (54.9\%), while children without vitamin D deficiency was $10(22.2 \%)$. The results of statistical analysis showed that there was a significant difference in the frequency of insulin resistance between the groups of vitamin D deficiency and vitamin D deficiency in obese children, with a value of $p=0.001(p<0.05)$. The odds ratio $(\mathrm{OR})=4.261(95 \%$ CI 1.744 10.411), which means that the risk of insulin resistance in obese children with vitamin D deficiency is 4.261 times greater than obese children who are not deficient in vitamin D (Table 5).

Table 5. Analysis of Frequency of Incidence of Insulin Resistance in group of Vitamin D Deficiency and group without Vitamin D Deficiency in Obese Children

\begin{tabular}{lllll}
\hline \multirow{2}{*}{ Vitamin D status } & \multicolumn{2}{c}{ Insulin Resistance } & Total & $p$-Value \\
\cline { 2 - 4 } & Yes & No & $51(100 \%)$ & \\
\hline Deficiency & $28(54.9 \%)$ & $23(45.1 \%)$ & $45(100 \%)$ & $0.001^{*}$ \\
Without Deficiency & $10(22.2 \%)$ & $35(77.8 \%)$ & $56(100 \%)$ & \\
Total & $38(39.6 \%)$ & $58(60.4 \%)$ & & 9 \\
\hline
\end{tabular}

* Chi-square test; OR=4.261 (CI 95\% 1.744-10.411).

\section{Discussion}

In this study, it was observed that there was no significant difference based on sex category of obese children between groups of vitamin D deficiency and without vitamin D deficiency. This result was similar to a study in Turkey which also stated there was no significant relationship based on sex between children with vitamin D deficiency and without vitamin D deficiency (Torun et al., 2013).

There was also no significant difference in the frequency of insulin resistance based on sex category. A similar result was found in a study in Jakarta (Pulungan et al., 2013). In contrast, A study by Kostovski in Macedonia showed that the percentage of female experienced insulin resistance was higher than the male with $p=0.009$ ( $p$ $<0.05$ ) (Kostovski et al., 2018). The explanation to this finding was because $52.94 \%$ of the female were in adolescence while $68.89 \%$ the male was in the pre-adolescent age. This difference may be related to age and puberty status of the study subjects.

There was no significant difference in the mean age in the groups of vitamin D deficiency and without vitamin D deficiency. A study in Italy by Rusconi also found no significant relationship between the mean age in children with vitamin D deficiency and without vitamin D deficiency (Rusconi et al., 2015).

There was also no significant difference in the mean age of insulin resistance and non-insulin resistance children. which means that age is not associated with the incidence of insulin resistance. This is incoherent with a study on 60 obese children with a mean age of $8.56 \pm 1.7$ years in Spain (Mastrangelo et al., 2016). Meanwhile, a study on 
220 obese children aged 5-14 years in Brazil found that the average age of children with insulin resistance was higher than in non-insulin resistance children (Romualdo et al., 2014).

Analysis of the incidence of insulin resistance in obese children with vitamin D deficiency and obese children without vitamin D deficiency showed a significant difference. So, it is recommended to examine the level of vitamin $\mathrm{D}$ and insulin resistance in obese children. The proposed biological mechanisms by which vitamin $\mathrm{D}$ influences insulin resistance in obesity include enhancing peripheral/hepatic uptake of glucose and reducing inflammation. The chronic inflammation that accompanied obesity develop to insulin resistance by the increased production of inflammatory cytokines from immune cell such as macrophages and adipocytes (Peterson et al., 2014). Similar to a study in China, it was stated that children with vitamin D deficiency had 4.15 times more at risk of developing insulin resistance than children without vitamin D deficiency (Fu et al., 2020). On the contrary, a study on 301 children aged 11-18 years in Turkey showed no significant relationship between insulin resistance and vitamin D status. The differences in the study population and gene polymorphism found in Turkey might make it different from our study. Besides, the study in Turkey divided vitamin D status into 3 categories, namely vitamin D deficiency (25-hydroxy vitamin D levels $<10 \mathrm{ng} / \mathrm{ml}$ ), vitamin D insufficiency (25-hydroxy vitamin D levels $10-20 \mathrm{ng} / \mathrm{ml})$, and normal vitamin D (25-hydroxy vitamin D content $>20 \mathrm{ng} / \mathrm{ml})$. It was indicating that other mechanisms cause insulin resistance other than vitamin D deficiency (Erdönmez et al., 2011).

In this study, there were 23 (45.1\%) obese children with vitamin D deficiency who does not experience insulin resistance. This might be due to the lack of data on how long the subjects had been obese and how long they had vitamin D deficiency. Although, this group had a risk of developing insulin resistance in the future. Likewise, it was also found that $10(22.2 \%)$ children without vitamin D deficiency had insulin resistance. The incidence of insulin resistance in obese children could happen as the result of other mechanisms, apart from the intermediary of vitamin D. Excessive energy in obesity can cause hyperplasia and hypertrophy of adipocytes resulting in oxidative stress. Oxidative stress from adipocytes triggers chronic inflammation in adipose tissue and produces free fatty acids and inflammatory mediators (van der Aa et al., 2015).

Children with vitamin D deficiency need vitamin D supplementation and adequate nutrition containing calcium and phosphate. Vitamin D supplementation is given orally as much as $1000 \mathrm{IU} /$ day for babies less than 1-month-old, 1000-5000 IU / day for babies aged 1-12 months old, and $5000 \mathrm{IU} /$ day for children over 12 months old, given for 2- 3 months. After 2-3 months, a control 25-hydroxy vitamin D level should be examined, then continued with vitamin D supplementation at a maintenance dose of $400 \mathrm{IU} /$ day, or $800 \mathrm{IU} /$ day for obese children. Monitoring of 25-hydroxy vitamin D levels shall be done in 6 months and 12 months afterward (Lee et al., 2013).

The limitation of this study is that the study was conducted in a cross-sectional manner, the data obtained were data at the time of sampling so that a causal analysis of obesity, vitamin D, and insulin resistance could not be provided. In this study, genetic factor analysis was not performed, however, its contribution could be minimized because the research samples were taken from the same population, namely from the same ethnicity.

The strength of this research is that the sample is randomly selected from schools with middle and upper economic status in Makassar so that it can describe the health condition of children with middle and upper economic status in Makassar. In addition, it is not necessary to analyze pubertal status because almost all study samples reflect puberty age.

The researchers concluded that the incidence of insulin resistance in the group of obese children with vitamin D deficiency was higher (54.9\%) compared to the group of obese children without vitamin D deficiency $(22.2 \%)$, in schools with middle and above socioeconomic levels. The risk of insulin resistance in obese children with vitamin D deficiency was 4,261 times greater than obese children without vitamin D deficiency. Researchers suggest the need for special attention to obese children, by conducting initial screening examinations for vitamin D tests and insulin resistance (fasting blood sugar and fasting insulin), as obese children have a risk of vitamin D deficiency and insulin resistance. The proactive intervention in obese children in managing obesity can prevent the risk of developing diabetes mellitus.

\section{Acknowledgments}

The authors have nothing to acknowledge.

\section{Competing Interests Statement}

The authors declare that there are no competing or potential conflicts of interest. 


\section{References}

Erdönmez, D., Hatun, S., Çizmecioğlu, F. M., \& Keser, A. (2011). No relationship between vitamin D status and insulin resistance in a group of high school students. Journal of Clinical Research in Pediatric Endocrinology, 3(4), 198-201. https://doi.org/10.4274/jcrpe.507

Fu, Z., Xu, C., Shu, Y., Xie, Z., Lu, C., \& Mo, X. (2020). Serum 25-hydroxyvitamin D is associated with obesity and metabolic parameters in US children. Public Health Nutrition, 23(7), 1214-1222. https://doi.org/10.1017/S1368980019001137

Garanty-Bogacka, B., Syrenicz, M., Goral, J., Krupa, B., Syrenicz, J., Walczak, M., \& Syrenicz, A. (2011). Serum 25-hydroxyvitamin D (25-OH-D) in obese adolescents. Endokrynologia Polska, 62(6), 506-511.

Govers, E. (2015). Obesity and Insulin Resistance Are the Central Issues in Prevention of and Care for Comorbidities. Healthcare (Basel, Switzerland), 3(2), 408-416. https://doi.org/10.3390/healthcare3020408

Greco, E. A., Lenzi, A., \& Migliaccio, S. (2019). Role of Hypovitaminosis D in the Pathogenesis of Obesity-Induced Insulin Resistance. Nutrients, 11(7). https://doi.org/10.3390/nu11071506

Kabadi, S. M., Lee, B. K., \& Liu, L. (2012). Joint effects of obesity and vitamin D insufficiency on insulin resistance and type 2 diabetes: results from the NHANES 2001-2006. Diabetes Care, 35(10), 2048-2054. https://doi.org/10.2337/dc12-0235

Kostovski, M., Simeonovski, V., Mironska, K., Tasic, V., \& Gucev, Z. (2018). Metabolic Profiles in Obese Children and Adolescents with Insulin Resistance. Open Access Macedonian Journal of Medical Sciences, 6(3), 511-518. https://doi.org/10.3889/oamjms.2018.097

Lee, J. Y., So, T.-Y., \& Thackray, J. (2013). A review on vitamin d deficiency treatment in pediatric patients. The Journal of Pediatric Pharmacology and Therapeutics : JPPT : The Official Journal of PPAG, 18(4), 277-291. https://doi.org/10.5863/1551-6776-18.4.277

Mastrangelo, A., Martos-Moreno, G. Á., García, A., Barrios, V., Rupérez, F. J., Chowen, J. A., ... \& Argente, J. (2016). Insulin resistance in prepubertal obese children correlates with sex-dependent early -onset metabolomic alterations. International Journal of Obesity (2005), 40(10), 1494-1502. https://doi.org/10.1038/ijo.2016.92

Peterson, C., Tosh, A. K., Balenchia, A. M. (2014). Vitamin D insufficiency and insulin resistance in obese adolesence. Therapeutic Advances in Endocrinology and Metabolism, 5(6), 166-189. https://doi.org/10.1177/2042018814547205

Peterson, C. (2015). Vitamin D deficiency and childhood obesity: interactions, implications, and recommendations. Nutrition and Dietary Supplements, 29. https://doi.org/10.2147/nds.s52024

Pulungan, A. B., Puspitadewi, A., \& Sekartini, R. (2013). Prevalence of insulin resistance in obese adolescents. Paediatrica Indonesiana, 53(3), 167. https://doi.org/10.14238/pi53.3.2013.167-72

Romualdo, M. C. dos S., Nóbrega, F. J. de, \& Escrivão, M. A. M. S. (2014). Insulin resistance in obese children and adolescents. Jornal de Pediatria, 90(6), 600-607. https://doi.org/10.1016/j.jped.2014.03.005

Roth, C. L., Elfers, C., Kratz, M., \& Hoofnagle, A. N. (2011). Vitamin d deficiency in obese children and its relationship to insulin resistance and adipokines. Journal of Obesity, 2011, 495101. https://doi.org/10.1155/2011/495101

Rusconi, R. E., De Cosmi, V., Gianluca, G., Giavoli, C., \& Agostoni, C. (2015). Vitamin D insufficiency in obese children and relation with lipid profile. International Journal of Food Sciences and Nutrition, 66(2), 132-134. https://doi.org/10.3109/09637486.2014.959902

Sung, C.-C., Liao, M.-T., Lu, K.-C., \& Wu, C.-C. (2012). Role of vitamin D in insulin resistance. Journal of Biomedicine \& Biotechnology, 2012, 634195. https://doi.org/10.1155/2012/634195

Torun, E., Gönüllü, E., Ozgen, I. T., Cindemir, E., \& Oktem, F. (2013). Vitamin d deficiency and insufficiency in obese children and adolescents and its relationship with insulin resistance. International Journal of Endocrinology, 2013, 631845. https://doi.org/10.1155/2013/631845

van der Aa, M. P., Fazeli Farsani, S., Knibbe, C. A. J., de Boer, A., \& van der Vorst, M. M. J. (2015). Population-Based Studies on the Epidemiology of Insulin Resistance in Children. Journal of Diabetes Research, 2015, 362375. https://doi.org/10.1155/2015/362375

Wu, H., \& Ballantyne, C. M. (2017). Skeletal muscle inflammation and insulin resistance in obesity. The Journal 
of Clinical Investigation, 127(1), 43-54. https://doi.org/10.1172/JCI88880

\section{Copyrights}

Copyright for this article is retained by the author(s), with first publication rights granted to the journal.

This is an open-access article distributed under the terms and conditions of the Creative Commons Attribution license (http://creativecommons.org/licenses/by/4.0/). 